\title{
Nephrotic syndrome-deafness-pretibial epidermolysis bullosa syndrome
}

INSERM

\section{Source}

INSERM. (1999). Orphanet: an online rare disease and orphan drug data base. Nephrotic syndrome-deafness-pretibial epidermolysis bullosa syndrome. ORPHA:300333

Nephrotic syndrome-deafness-pretibial epidermolysis bullosa syndrome is a rare, genetic, renal disease characterized by hereditary nephritis leading to nephrotic syndrome and end-stage renal failure associated with sensorineural hearing loss and pretibial skin blistering followed by atrophy. Other reported manifestations include bilateral lacrimal duct stenosis, dystrophic teeth and nails, bilateral cervical ribs, unilateral kidney, distal vaginal agenesis and anemia due to beta-thalassemia minor. 